\title{
Genetic analysis of muscular dystrophies: our experience in Mexico
}

\author{
Rosa Elena Escobar-Cedillo${ }^{1}$, Luz Berenice López-Hernández ${ }^{2}$, Antonio Miranda-Duarte ${ }^{1}$, María Dolores Curiel-Leal ${ }^{1}$, \\ Andrea Suarez-Ocón ${ }^{1}$, Laura Sánchez-Chapul ${ }^{1}$, Alexandra Berenice Luna-Angulo ${ }^{1}$, Guillermina Ávila-Ramírez ${ }^{3}$, \\ Julia Angélica López-Hernández ${ }^{4}$, Benjamín Gómez-Díaz ${ }^{1}$ \\ ${ }^{1}$ Instituto Nacional de Rehabilitación Luis Guillermo Ibarra Ibarra, Ciudad de México, México, ${ }^{2}$ Universidad Autónoma de \\ Guadalajara, Zapopan, Mexico; ISSSTE-Centro Médico Nacional 20 de Noviembre, ${ }^{3}$ Universidad Nacional Autónoma de México, \\ México, ${ }^{4}$ Department of Human Genetics, Leiden University Medical Center, Leiden, The Netherlands
}

\begin{abstract}
Muscular dystrophies are a group of well-defined genetic disorders characterized by the variable distribution of muscle wasting and progressive weakness. The diagnosis and treatment of these diseases remain challenging due to genetic heterogeneity and clinical overlapping. Herein, we describe our 10 years' experience with the diagnosis and management of muscular dystrophy patients. In total, 169 patients were screened for pathogenic variants in eleven genes linked to frequent muscular dystrophies using MLPA and NGS sequencing panels. Most frequent muscular dystrophies found in the Mexican population were dystrophinopathies, dysferlinopathies and calpainopathies. Novel variants were found in genes: DMD, CAPN3, DYSF, and FKRP. For Duchenne muscular dystrophy, improvements in early diagnosis and prolonged ambulation were achieved, on the contrary, for limb-girdle muscular dystrophies and congenital muscular dystrophies, uncomplimentary follow-up and lack of detection strategies were observed. For most common muscular dystrophies, improvements in diagnosis and management have been achieved in the last 10 years, due to a collaborative effort done nationwide.
\end{abstract}

Key words: muscular dystrophy, DMD, limb-girdle, Pompe, Mexico.

\section{Introduction}

Muscular dystrophies (MDs) are a clinically heterogeneous group of hereditary disorders characterized by progressive muscle weakness. MDs lead to disability and in some cases, early death. Depending on MD type, limb, axial, and facial muscles can be affected to a variable degree, and in specific forms, other organs or tissues can be also involved including the brain. Therefore, the severity, age at onset, disease progression, complications, and prognosis also vary greatly among different forms of $M D$, with significant implications for genetic counselling and treatment $[7,9,23,25]$.

The advance and availability of molecular genetic tools have allowed the identification of several genes involved in MDs. To date, more than 40 genes have been related to MDs, and the list of genes is still growing [18]. In general, the MDs are recognized as follows: Duchenne and Becker dystrophies (DMD/ $B M D$ ), myotonic dystrophy (MD1 and 2), facioscapu-

\section{Communicating author}

Benjamín Gomez-Díaz, MSc, Instituto Nacional de Rehabilitación Luis Guillermo Ibarra Ibarra, Ciudad de México 14389, México,

e-mail: bngomez@inr.gob.mx 
lohumeral (FSHD), limb-girdle (LGMD), congenital (CMD), Emery-Dreifuss (EDMD) and oculopharyngeal muscular dystrophies (OPMD). Molecular tests and gene expression analyses have made it possible to accurately diagnose MDs and carry out specific anticipatory care interventions for cardiac and respiratory complications.

DMD/BMD are the most common forms of inherited muscular dystrophies. Their prevalence in the general population is $4.78 / 100,000$, and frequency in males is 1 in 3,500-5,000 and 1 in 18,000; respectively. DMD is characterized by rapidly progressive proximal weakness. It usually begins in early childhood with delayed milestones (e.g., sitting and standing independently), waddling gait, difficulty to climb, and wheelchair dependency by 13 years. Respiratory complications and cardiomyopathy are common causes of death. BMD has later onset and patients could remain ambulatory beyond their 20s. Survival surpasses 40 years, with dilated cardiomyopathy being a common cause of death. DMD/BMD are caused by mutations in the dystrophin gene $(D M D)$ in Xp21, which results in absent or non-functional muscle dystrophin in DMD and shortened or partially functional protein in BMD [1].

Myotonic dystrophy is an autosomal dominant disorder considered the most common MD in adults. Its prevalence in the general population is 8.26 per 100,000 . Classically, it is characterized by muscular weakness, myotonia, early-onset cataracts, balding, hypogonadism, and cardiac arrhythmia, although the congenital form shows hypotonia and severe generalized weakness. Myotonic dystrophy type 1 is due to an abnormally expanded CTG repeat in the 3'-untranslated region of the dystrophia myotonica protein kinase gene (DMPK) on 19q13.3. Myotonic dystrophy type 2 results from an unstable CCTG repeat expansion in the first intron of zinc finger protein-9 gene (ZNF9) on 3q21.3 [29].

Facioscapulohumeral muscular dystrophy (FSHD) is inherited in an autosomal dominant fashion. It is considered the third most common MD, with a prevalence of 3.95 per 100,000 . FSHD is characterized by weakness involving facial, shoulder, and upper arm musculature, with a progression to the pelvic girdle and lower limb. The age of onset ranges from 10 to 30 years old. FSHD type 1 is caused by contraction of the D4Z4 microsatellite repeat in the sub telomeric region of $4 q 35$. While FSHD type 2 is caused by the combination of heterozygous mutations in struc- tural maintenance of chromosomes flexible hinge domain containing 1 gene (SMCHD1) on 18p11.32 and presence of a haplotype on chromosome 4 that is permissive for DUX4 expression [26].

Taken as a group, limb-girdle muscular dystrophy (LGMD) is the fourth most common MD, with a pooled prevalence of 1.63 per 100,000 [16]. LGMDs are a highly heterogeneous group of MDs characterized by weakness of pelvic and shoulder musculature, and whose onset may be either in childhood or adulthood [27]. These are classified according to the inheritance as autosomal dominant and autosomal recessive, named LGMD1 and LGMD2, respectively. To date, there have been 8 types of LGMD1 (LGMD1A-1H) and 26 types of LGMD2 (LGMD2A-2Z). LGMDs are caused by mutations in different genes that encode proteins with a wide range of functions and locations among which we can mention, extracellular matrix, cell membrane, and nucleus [6].

Congenital muscular dystrophies (CMD) are diseases distinguished by early-onset, hypotonia, muscle weakness, and dystrophic features with an estimated prevalence of 0.99 (Cl: 0.62-1.57) per 100,000 individuals [16].

Emery-Dreifuss muscular dystrophy (EDMD) is a rare entity, with a prevalence of 0.39 per 100,000. Typically, it is presented by progressive weakness, flexion deformities of the elbows, and cardiac abnormalities. This entity shows genetic heterogeneity; however, the X-linked DM is the most frequent form and is caused by mutations in the emerin gene $(E M D)$ at $\mathrm{Xq} 28$ [11].

Oculopharyngeal muscular dystrophy (OPMD) is a rare autosomal dominant disorder. It is characterized by progressive ptosis, dysphagia, and proximal leg weakness, whose onset is after 40 years of age. Its prevalence is 0.13 per 100,000 . OPMD is caused by a GCG repeat in the first exon of poly(A)-binding protein-2 gene (PABN1) located on 14q11.2 [22].

Muscular dystrophies may present clinical overlapping, making diagnosis difficult [2]. A study showed that $12 \%$ of patients clinically diagnosed as $D M D / B M D$ were indeed LGMD with pathogenic variants in the fukutin-related protein (FKRP) gene [23]. In Mexico, 3.3\% of patients with presumptive diagnoses of $\mathrm{DMD} / \mathrm{BMD}$ demonstrated mutations in FKRP that lead to LGMD2I, which has a different inheritance pattern and recurrence risk [20]. It is also worthy of noting that for treatment, genetic testing could make a difference; for DMD 
patients deflazacort has shown benefits, whereas for LGMD2B patients the same drug may represent a risk [25]. Therefore, differential diagnosis and confirmation by genetic testing in MDs are important because: 1) they allows carrier detection and estimating recurrence risks for genetic counselling, 2) steroid treatment depends on the definite diagnosis of cases, and 3) clinical trials for novel molecular therapies often require the exact delineation of the disease-causing variant [13].

The frequency of MDs may vary among populations due to inbreeding, migration, founder effect, and bottlenecks $[4,21]$. In Mexico, our group has previously described the prevalence of MDs by immunodetection analysis; nevertheless, it remains to be confirmed by molecular genetic analyses. The estimated prevalence found in our previous study was: $52.36 \%$ for dystrophinopathies, $18.40 \%$ dysferlinopathies, $14.15 \%$ sarcoglycanopathies, $11.32 \%$ calpainopathies, $1.89 \%$ merosinopathies, $1.42 \%$ caveolinopathies, and $0.47 \%$ emerinopathies. Deficiencies in lamin A/C and telethonin were not detected [10]. A recent study in Mexican patients revealed that $12.5 \%$ of patients who were negative for DMD gene mutations, were positive for pathogenic variants in LGMD related genes and reported a suspicious absence of dysferlinopathies [3]. Recently, a study showed that during the confirmation of the results of the screening of Pompe disease in Latin America, dysferlinopathies were the second most common type of LGMDs [16]. Discrepancies among these studies may occur because none of the above-mentioned studies was aimed to describe a broad range of patients with myopathies. None of the above-mentioned studies was aimed to describe the road to precision diagnosis in MDs in Mexico. Herein, we describe our 10 years' experience with patients with muscular dystrophy.

\section{Material and methods \\ Patient population}

We analysed 169 samples of patients who were clinically diagnosed as probable MD from the following institutions: Instituto Nacional de Rehabilitación Luis Guillermo Ibarra Ibarra, Asociación de Distrofia Muscular de Occidente A.C, and Centro Médico Nacional "20 de Noviembre" ISSSTE. Patients included in this analysis were referred to this group of study from January 2010 to March 2020.
Our study was approved by the local Investigation and Ethics committee of ISSSTE with reference no. 094.2013.

\section{Clinical evaluation}

Patients were evaluated according to standard criteria for MDs. The assessment included recorded proximal and/or distal weakness, positive Gower manoeuvre, age at onset, serum creatine kinase (CK) levels, family history, and electromyography. Biopsy or DNA samples were taken after written informed consent was given in adult patients, or by parents in the case of affected children.

\section{DNA extraction}

For Multiplex Ligation-dependent Probe Amplification (MLPA) analysis, genomic DNA was extracted from peripheral lymphocytes using the CTAB-DTAB method and quantified using a Nanodrop ND-1000 spectrophotometer (Thermo Fisher Scientific, Waltham, MA, USA). DNA samples for NGS were taken and processed as described previously [5].

\section{MLPA}

MLPA assays were performed using $100 \mathrm{ng}$ of DNA as described previously [13]. Detection of copy number variations of all exons of the $D M D$ gene was performed using MLPA according to manufacturer's instructions (P034/P035, MRC-Holland, Amsterdam, The Netherlands) and analysed using Genemarker V1.91 software as described previously [13] (without PM-MLPA procedure).

\section{Next-generation sequencing}

The genes covered by two panels used in this study were 1) DMD (MIM*300377, Xp21.2-p21.1, NM_004006.2) and 2) ANO5 (MIM*608662, 11p14.3), CAPN3 (MIM*114240, 15q15.1, NM 000070.2), DYSF (MIM*603009, 2p13.2, NM_003494.3), FKRP $\left(M^{*} M^{*} 606596, \quad 19 q 13.32, \quad N M \_024301.4\right), \quad S G C A$ $\left(M^{*} M^{*} 600119,17 q 21.33\right), \quad S G C B \quad\left(M^{*} M^{*} 600900\right.$, 4q12), SGCD (MIM*601411, 5q33.2-q33.3), SGCG $\left(M^{*} M^{*} 608896,13 q 12.12\right)$, TCAP $\left(M^{*}{ }^{*} 604488\right.$, 17q12.2), and GAA (MIM*606800, 17q25.2-q25.3) sequencing was performed by a private diagnostic laboratory as described by others [5].

The variant classification described herein complies with considerations of the American College of Medical 
Table I. Frequencies of variants among patients with any variant identified by the MLPA and NGS gene panels

\begin{tabular}{|c|c|c|c|c|c|c|}
\hline Genes & Disease & $\begin{array}{l}\text { Patients } \\
n=115\end{array}$ & $\begin{array}{c}\text { Females } \\
(\%)\end{array}$ & $\begin{array}{c}\text { Males } \\
(\%)\end{array}$ & $\begin{array}{c}\text { Age at } \\
\text { diagnosis } \\
\text { (range years) }\end{array}$ & $\begin{array}{c}\text { Family history } \\
(\%)\end{array}$ \\
\hline$D M D$ & DMD Dystrophin-related & 67 & $0(0)$ & $60(100)$ & $2-7$ & $17(25.4)$ \\
\hline$D M D$ & BMD Dystrophin-related & 4 & $0(0)$ & $4(100)$ & $19-37$ & $1(25)$ \\
\hline ANO5 & LGMD R12 Anoctamin5-related & 1 & $1(100)$ & $0(0)$ & 12 & $1(100)$ \\
\hline CAPN3 & LGMD R1 Calpain3-related & 13 & $7(53.8)$ & $6(46.2)$ & $9-61$ & $5(38.5)$ \\
\hline DYSF & LGMD R2 Dysferlin-related & 17 & $6(35.3)$ & $11(64.7)$ & $2-37$ & $4(31)$ \\
\hline FKRP & LGMD R9 Dystroglycan-related & 4 & $3(75)$ & $1(25)$ & $3-35$ & $1(25)$ \\
\hline SGCA & LGMD R3 Sarcoglycan-related & 3 & $0(0)$ & $3(100)$ & $2-14$ & $0(0)$ \\
\hline$S G C B$ & LGMD R4 Sarcoglycan-related & 2 & $0(0)$ & $2(100)$ & $3-5$ & $2(100)$ \\
\hline$S G C D$ & LGMD R6 Sarcoglycan-related & 1 & $0(0)$ & $1(100)$ & 6 & $0(0)$ \\
\hline$S G C G$ & LGMD R5 Sarcoglycan-related & 1 & $0(0)$ & $1(100)$ & 27 & $0(0)$ \\
\hline TCAP & LGMD R7 Telethonin-related & 0 & $0(0)$ & $0(0)$ & 0 & $0(0)$ \\
\hline$G A A$ & Glycogen storage disease type II & 2 & $0(0)$ & $2(100)$ & $3-5$ & $2(100)$ \\
\hline
\end{tabular}

Genetics and Genomics (ACMG-American College of Medical Genetics) (PMID: 25741868), being classified as pathogenic, probably pathogenic (probability greater than $90 \%$ of being pathogenic), of significance uncertain, probably benign (greater than $90 \%$ probability of being benign) and benign. In this publication, only pathogenic, probably pathogenic and variants of uncertain significance are reported which present an impact prediction for the structure and function of the protein and are related to the clinical picture of the patient.

\section{Results}

\section{Disease-causing variant detection}

In total 169 patients were screened for pathogenic variants in 11 genes linked to frequent muscular dystrophies. The number of patients with pathogenic variants found $n=115$, and negative diagnosis $n=54$ (Table I). For dystrophinopathies (DMD/BMD) seven novel variants were found (not previously reported in the LOVD database) and are shown in Table II. In patients in which no pathogenic variants were found, $83.3 \%$ correspond to LGMD and $16.7 \%$ to DMD/BMD. The overall percentage of patients with detected variants was $68 \%$ and $32 \%$ of negative results, respectively. In this study, 18 novel variants were found in genes DMD, DYSF, CAPN and FKRP (Table II). Variant effect prediction was performed using Ensembl Variant Effect Predictor (VEP) online tool (https://grch37.ensembl.org/info/docs/ tools/vep/index.html) [17].

\section{Clinical management of muscular dystrophies}

\section{Duchenne/Becker muscular dystrophies}

In this study the mean age at diagnosis in DMD patients was $3.6 \pm 1.49$ and the mean age at loss of ambulation in patients that underwent steroid treatment was $12.04 \pm 3.32$ years. With regard to BMD, patients who suffer a subtler disease presentation, all receive physical therapy and cardiorespiratory issues with trained specialists.

\section{Limb-girdle muscular dystrophies}

The genetic heterogeneity and clinical overlapping that occurs among LGMD makes diagnosis and management more challenging, in this study $48.42 \%$ of all LGMD patients are under follow-up whereas $51.57 \%$ of patients lost communication with the above-mentioned institutions so physical therapy, disease progression monitoring, and genetic counselling require additional work to improve health access and life quality in these patients. The frequencies of genetic variants found in this study are shown in Table III compared to those reported in other studies [3,15,24,28].

\section{Other muscular dystrophies}

Due to the clinical similarities among MDs, only LGMD and DMD/BMD were included in the present study. Other types of MD such as myotonic, con- 
Table II. Novel variants found in this study

\begin{tabular}{|c|c|c|c|c|}
\hline Gene & Variant & Change consequence & Exon & Variant effect prediction \\
\hline DMD & c.(?_-244)_(6438+1_6439-1)del & p.? & 1 1_44i & Probably pathogenic \\
\hline DMD & c.(649+1_650-1)_(1149+1_1150-1)del & p.? & 7i_10i & Probably pathogenic \\
\hline DMD & c.(960+1_961-1)_(1149+1_1150-1)dup & p.? & 9i_10i & Variant of uncertain significance (VUS) \\
\hline DMD & c. $7745 \mathrm{C}>\mathrm{A}$ & p. $($ Ser2582*) & 53 & Probably pathogenic, frameshift \\
\hline DMD & c.3036_3037delinsAT & p.(Glu1013*) & 23 & Probably pathogenic, frameshift \\
\hline DMD & C.877A $>\mathrm{T}$ & p.(Lys293*) & 9 & Probably pathogenic, frameshift \\
\hline$D M D$ & $c .283 G>T$ & p. $($ Gly95*) & 5 & Probably pathogenic, frameshift \\
\hline CAPN3 & c.1331_1332dup & p.(Gly445Profs`19) & 10 & Probably pathogenic, frameshift \\
\hline CAPN3 & $c .1456 C>T$ & p. $\left(\mathrm{G} \ln 486^{\star}\right)$ & 11 & $\begin{array}{l}\text { Premature stop codon, probably_ } \\
\text { damaging }\end{array}$ \\
\hline CAPN3 & c.1501A>G & p.Thr501Ala & 11 & $\begin{array}{c}\text { SIFT: deleterious } \\
\text { PolyPhen: probably_damaging }\end{array}$ \\
\hline CAPN3 & c.1984G>C & p.(Ala662Pro) & 17 & $\begin{array}{c}\text { SIFT: deleterious } \\
\text { PolyPhen: probably_damaging }\end{array}$ \\
\hline CAPN3 & c.347C >A & p.(Ala116Asp) & 2 & $\begin{array}{c}\text { SIFT: deleterious } \\
\text { PolyPhen: probably_damaging }\end{array}$ \\
\hline DYSF & $c .1457 C>T$ & p.(Ser486Phe) & 16 & $\begin{array}{c}\text { SIFT: deleterious } \\
\text { PolyPhen: probably_damaging }\end{array}$ \\
\hline DYSF & c. $2437 C>G$ & p.(Gln813Glu) & 24 & Probably pathogenic \\
\hline DYSF & c. $4509+11 T>A$ & p.? & $42 \mathrm{i}$ & Variant of uncertain significance (VUS) \\
\hline DYSF & c.6049del & p.(Asp2017Thrfs*19) & 54 & Probably pathogenic, frameshift \\
\hline DYSF & c.6057-8G>A & p.? & $53 i$ & Variant of uncertain significance (VUS) \\
\hline FKRP & c. $1312 \mathrm{G}>\mathrm{A}$ & p.(Asp438Asn) & 4 & $\begin{array}{c}\text { SIFT: deleterious } \\
\text { PolyPhen: probably damaging }\end{array}$ \\
\hline
\end{tabular}

Table III. Frequency of the most common limb-girdle muscular dystrophy (LGMD) in different populations

\begin{tabular}{|lcccccc|}
\hline Genes & Disease & $\begin{array}{c}\text { This study } \\
n=44\end{array}$ & $\begin{array}{c}\text { Mexico } \\
\text { (paediatric cohort) } \\
n=11[3]\end{array}$ & $\begin{array}{c}\text { Italy } \\
n=13[15]\end{array}$ & $\begin{array}{c}\text { Canada } \\
n=54[24]\end{array}$ & $\begin{array}{c}\text { China } \\
n=93[28]\end{array}$ \\
\hline ANO5 & LGMD R12 Anoctamin5-related & 1 & 0 & 2 & 5 & 1 \\
\hline CAPN3 & LGMD R1 Calpain3-related & 13 & 1 & 5 & 17 & 27 \\
\hline DYSF & LGMD R2 Dysferlin-related & 17 & 0 & 3 & 10 & 52 \\
\hline FKRP & LGMD R9 Dystroglycan-related & 4 & 1 & 1 & 10 & 3 \\
\hline SGCA & LGMD R3 Sarcoglycan-related & 3 & 2 & 0 & 4 & 8 \\
\hline SGCB & LGMD R4 Sarcoglycan-related & 2 & 3 & 0 & 0 & 1 \\
\hline SGCD & LGMD R6 Sarcoglycan-related & 1 & 2 & 0 & 0 & 1 \\
\hline SGCG & LGMD R5 Sarcoglycan-related & 1 & 2 & 0 & 0 & 0 \\
\hline TCAP & LGMD R7 Telethonin-related & 0 & 0 & 1 & 0 & 0 \\
\hline GAA & Glycogen storage disease type II & 2 & NA & 1 & 8 & 0 \\
\hline
\end{tabular}

genital, facioscapulohumeral and oculopharyngeal muscular dystrophy cases were referred to research groups in and outside Mexico [14,19].

\section{Discussion}

Herein we implemented a diagnostic strategy for routine genetic diagnostic combining MLPA and NGS-based panels directed to DMD/LGMD. In Mex- ico, our group described before the prevalence of MDs by immunodetection analysis; nevertheless, it remained to be confirmed by genetic analyses until now. The estimated prevalence found in our previous study was: $52.36 \%$ dystrophinopathies, $18.40 \%$ dysferlinopathies, $14.15 \%$ sarcoglycanopathies, $11.32 \%$ calpainopathies, $1.89 \%$ merosinopathies, $1.42 \%$ caveolinopathies, and $0.47 \%$ emerinopathies. Deficiencies 
in lamin $A / C$ and telethonin were not detected [10]. This is partially concordant with the results reported in the present study, dystrophinopathies are the most frequently found type of MD followed by dysferlinopathies; nevertheless, calpainopathies were not appropriately detected by immunodetection analysis because most pathogenic variants in the CAPN3 gene occur due to the loss of calpain-3 autolytic activity [8] not due to the absence of the protein in muscle biopsies, this may explain differences between our previous study and the present work.

Currently there is no clinical consensus regarding the combination of genes that should be analysed by NGS in specific groups of patients. Interestingly, inner population dynamics may modify the frequency of disease-causing variants found within the same country. Phenomena like inbreeding, migration, founder effect, and bottlenecks may explain the high frequency of certain MDs. Recently, two studies explored the presence of genetic variants in patients with neuromuscular disorders, but the type of patients and variants found in these studies depend on the main objective of the clinical examination. In patients of paediatric age, it is more common to find pathogenic variants in $D M D$, sarcoglycan and FKRP genes, and absence of mutations the dysferlin gene [3], whereas for differential diagnosis of glycogen storage disease type II (Pompe) it is indeed common to find pathogenic variants in the dysferlin gene [5]. Therefore, a broad group of phenotypes and clinical presentations as included in this study, may contribute to the knowledge of a wider spectrum of muscular dystrophies in our country. Except for the CMD group, since the severity of symptoms and the lack of national guidelines to manage such patients result in early death of undiagnosed patients and the need of international collaborations to achieve diagnosis.

With regard of the common group of dystrophinopathies, BMD patients who suffer a subtler disease presentation than DMD patients, all receive physical therapy and cardiorespiratory issues are addressed by trained specialists at the Instituto Nacional de Rehabilitación Luis Guillermo Ibarra Ibarra (INRLGII) facilities. On the other hand, patients suffering from DMD receive better medical care compared to past years. It was previously shown by our group that there was a delay in diagnosis of DMD patients with the mean age at diagnosis being $5.72 \pm 3.31$ years and only about $35 \%$ of patients received corticosteroid treatment, intervention that is recommended in the standards of care in most developed countries and therefore the mean age at loss of ambulation was $9.79 \pm 2.21$ years without deflazacort/prednisone treatment [12]. In the present study, the mean age at diagnosis was $3.6 \pm 1.49$ and the mean age at loss of ambulation in patients that underwent steroid treatment was $12.04 \pm 3.32$ years. Therefore, in our experience, improvements in crucial ages to delay disease progression were achieved herein.

\section{Conclusions}

Knowledge of the genetic variants that cause muscular dystrophies in a particular population facilitate the generation of diagnostic strategies, accelerate the appropriate treatment for patients, and allow genetic counselling and the estimation of recurrence risks.

For dystrophinopathies (DMD/BMD), the accumulation of knowledge has allowed clearer treatment guidelines and significant improvements in life expectancy and quality of life, but for the rest of muscular dystrophies, more research and translational strategies that benefit patients are necessary. Variant effect prediction, combining structural variant detection techniques and the search for deep intronic pathogenic variants are of utmost importance even when NGS is used since in autosomal recessive MDs two pathogenic variants are expected to explain the phenotype and in many cases this is not possible with low resolution mutation detection techniques (supplementary material individual variants found in this study).

For early-onset girdle muscular dystrophies in the Mexican population, once the pathogenic variants in the DMD gene have been ruled out, it is necessary to emphasize the need for molecular tests that include sarcoglycans and FKRP, while for late-onset girdle muscular dystrophies it is convenient include the dysferlin gene and make the differential diagnosis with late-onset Pompe disease.

\section{Funding}

This work was supported by CONACYT under reference no. 262150 and by E-015 Investigación y Desarrollo Tecnológico.

\section{Acknowledgments}

We thank all participants, Sociedad Mexicana de la Distrofia Muscular A.C. and Asociación de Distro- 
fia Muscular de Occidente A.C. We would also like to thank CENTOGENE laboratory, PTC Therapeutics, DLE Laboratory and Sanofi-Genzyme for support in genetic analysis.

\section{Disclosure}

The authors declare no conflict of interest. The funders (CONACYT and ISSSTE) are part of the public health and education systems in Mexico and had no role in the design of the study; in the collection, analyses, or interpretation of data; in the writing of the manuscript, or in the decision to publish the results.

\section{References}

1. Aartsma-Rus A, Ginjaar IB, Bushby K. The importance of genetic diagnosis for Duchenne muscular dystrophy. J Med Genet 2016; 53: 145-151.

2. Al-Harbi KM, Abdallah AM. LGMD2D syndrome: the importance of clinical and molecular genetics in patient and family management. Case report. Neuro Endocrinol Lett 2016; 37: 277-281.

3. Alcántara-Ortigoza MA, Reyna-Fabián ME, González-Del Angel A Estandia-Ortega B, Bermúdez-López C, Cruz-Miranda GM, RuízGarcía M. Predominance of dystrophinopathy genotypes in Mexican male patients presenting as muscular dystrophy with a normal multiplex polymerase chain reaction. Genes (Basel) 2019; 10: 856.

4. Argov Z. Neuromuscular disorders in Israel: a model country for ethnic clusters. Neuromuscul Disord 2019; 29: 269-273.

5. Bevilacqua JA, Guecaimburu Ehuletche MDR, Perna A, Dubrovsky A, Franca MC, Vargas S, Hegde M, Claeys KG, Straub V, Daba N, Faria R, Periquet M, Sparks S, Thibault N, Araujo R. The Latin American experience with a next generation sequencing genetic panel for recessive limb-girdle muscular weakness and Pompe disease. Orphanet J Rare Dis 2020; 15: 11.

6. Chu ML, Moran E. The limb-girdle muscular dystrophies: is treatment on the horizon? Neurotherapeutics 2018; 15: 849-862.

7. Emery AE. The muscular dystrophies. Lancet 2002; 359: 687-695.

8. Fanin M, Nascimbeni AC, Angelini C. Screening of calpain-3 autolytic activity in LGMD muscle: a functional map of CAPN3 gene mutations. J Med Genet 2007; 44: 38-43.

9. Golla S, Agadi S, Burns DK, Marks W, Dev Batish S, del Gaudio D, lannaccone ST. Dystrophinopathy in girls with limb girdle mus cular dystrophy phenotype. J Clin Neuromuscul Dis 2010; 11: 203-208.

10. Gómez-Díaz B, Rosas-Vargas H, Roque-Ramírez B, Meza-Espinoza P, Ruano-Calderón LA, Fernández-Valverde F, Escalante-Bautista D, Escobar-Cedillo RE, Sánchez-Chapul L, Vargas-Cañas S, López-Hernández LB, Bahena-Martínez E, Luna-Angulo AB, Canto P, Coral-Vázquez RM. Immunodetection analysis of muscular dystrophies in Mexico. Muscle Nerve 2012; 45: 338-345.

11. Heller SA, Shih R, Kalra R, Kang PB. Emery-Dreifuss muscular dystrophy. Muscle Nerve 2020; 61: 436-448.

12. López-Hernández LB, Gómez-Díaz B, Escobar-Cedillo RE, GamaMoreno O, Camacho-Molina A, Soto-Valdés DM, Anaya-Se- gura MA, Luna-Padrón E, Zúñiga-Guzmán C, Lopez-Hernández JA, Vázquez-Cárdenas NA, Sánchez-Chapul L, RangelVillalobos H, Canto P, López-Cardona MG, García S, MéndezCovarrubias G, Coral-Vázquez RM. Duchenne muscular dystrophy in a developing country: challenges in management and genetic counseling. Genet Couns 2014; 25: 129-141.

13. López-Hernández LB, Gómez-Díaz B, Luna-Angulo AB, Anaya-Segura $M$, Bunyan DJ, Zúñiga-Guzman C, Escobar-Cedillo RE, Roque-Ramírez B, Ruano-Calderón LA, Rangel-Villalobos $H$, López-HernándezJA, Estrada-Mena FJ, García S, Coral-Vázquez RM. Comparison of mutation profiles in the Duchenne muscular dystrophy gene among populations: implications for potential molecular therapies. Int J Mol Sci 2015; 16: 5334-5346.

14. Magaña JJ, Cortés-Reynosa P, Escobar-Cedillo R, Gómez R, LeyvaGarcía N, Cisneros B. Distribution of CTG repeats at the DMPK gene in myotonic dystrophy patients and healthy individuals from the Mexican population. Mol Biol Rep 2011; 38: 1341-1346.

15. Magri F, Nigro V, Angelini C, Mongini T, Mora M, Moroni I, Toscano A, D’Angelo MG, Tomelleri G, Siciliano G, Ricci G, Bruno C, Corti S, Musumeci O, Tasca G, Ricci E, Monforte M, Sciacco M, Fiorillo C, Gandossini S, Minetti C, Morandi L, Savarese M, Di Fruscio G, Semplicini C, Pegoraro E, Govoni A, Brusa R, Del Bo R, Ronchi D, Moggio M, Bresolin N, Comi GP. The Italian limb girdle muscular dystrophy registry: Relative frequency, clinical features, and differential diagnosis. Muscle Nerve 2017; 55: 55-68.

16. Mah JK, Korngut L, Fiest KM, Dykeman J, Day LJ, Pringsheim T, Jette $\mathrm{N}$. A systematic review and meta-analysis on the epidemiology of the muscular dystrophies. Can J Neurol Sci 2016; 43: 163-177.

17. McLaren W, Gil L, Hunt SE, Riat HS, Ritchie GR, Thormann A, Flicek P, Cunningham F. The ensembl variant effect predictor. Genome Biol 2016; 17: 122.

18. Mercuri E, Bönnemann CG, Muntoni F. Muscular dystrophies. Lancet 2019; 394: 2025-2038.

19. Murillo-Melo NM, Márquez-Quiróz LC, Gómez R, Orozco L, Mendoza-Caamal E, Tapia-Guerrero YS, Camacho-Mejorado R, Cortés H, López-Reyes A, Santana C, Noris G, Hernández-Hernández O, Cisneros B, Magaña JJ. Origin of the myotonic dystrophy type 1 mutation in Mexican population and influence of Amerindian ancestry on CTG repeat allelic distribution. Neuromuscul Disord 2017; 27: 1106-1114.

20. Navarro-Cobos MJ, González-Del Angel A, Estandia-Ortega B, Ruiz-Herrera A, Becerra A, Vargas-Ramírez G, Bermúdez-López C, Alcántara-Ortigoza MA. Molecular analysis confirms that FKRP-related disorders are underdiagnosed in mexican patients with neuromuscular diseases. Neuropediatrics 2017; 48: 442-450.

21. Pantoja-Melendez CA, Miranda-Duarte A, Roque-Ramirez B, Zenteno JC. Epidemiological and molecular characterization of a Mexican population isolate with high prevalence of limb-girdle muscular dystrophy type 2A due to a novel calpain-3 mutation. PLoS One 2017; 12: e0170280.

22. Raz V, Butler-Browne G, van Engelen B, Brais B. 191st ENMC international workshop: recent advances in oculopharyngeal muscular dystrophy research: from bench to bedside 8-10 June 2012, Naarden, The Netherlands. Neuromuscul Disord 2013; 23 : 516-523. 
23. Schwartz M, Hertz JM, Sveen ML, Vissing J. LGMD2I presenting with a characteristic Duchenne or Becker muscular dystrophy phenotype. Neurology 2005; 64: 1635-1637.

24. Thuriot F, Gravel E, Buote C, Doyon M, Lapointe E, Marcoux L, Larue S, Nadeau A, Chenier S, Waters PJ, Jacques PE, Gravel S, Lévesque S. Molecular diagnosis of muscular diseases in outpatient clinics: a Canadian perspective. Neurol Genet 2020; 6: e408.

25. Walter MC, Reilich P, Thiele S, SchessI J, Schreiber H, Reiners K, Kress W, Müller-Reible C, Vorgerd M, Urban P, Schrank B, Deschauer M, Schlotter-Weigel B, Kohnen R, Lochmüller $H$. Treatment of dysferlinopathy with deflazacort: a double-blind, placebo-controlled clinical trial. Orphanet J Rare Dis 2013; 8: 26.

26. Wang LH, Tawil R. Facioscapulohumeral dystrophy. Curr Neurol Neurosci Rep 2016; 16: 66.

27. Wicklund MP. The limb-girdle muscular dystrophies. Continuum (Minneap Minn) 2019; 25: 1599-1618.

28. Yu M, Zheng Y, Jin S, Gang Q, Wang Q, Yu P, Lv H, Zhang W, Yuan Y, Wang Z. Mutational spectrum of Chinese LGMD patients by targeted next-generation sequencing. PLoS One 2017; 12: e0175343.

29. Yum K, Wang ET, Kalsotra A. Myotonic dystrophy: disease repeat range, penetrance, age of onset, and relationship between repeat size and phenotypes. Curr Opin Genet Dev 2017; 44: 30-37. 